\title{
EFFECTS OF WIRELESS MOBILE TECHNOLOGY ON EMPLOYEE WORK BEHAVIOR AND PRODUCTIVITY: An Intel Case Study ${ }^{1}$
}

\author{
Majorkumar Govindaraju \\ David Sward \\ Intel Corporation \\ Santa Clara, CA
}

Wireless mobility is impacting business and home users by changing the way we work and live (Lyytinen and Yoo 2002). Research studies have modeled the patterns of use in ubiquitous computing environments (Cousins and Robey 2003). Intel began migrating users from Intel $($ Pentium $(\mathbb{B}$ II processor-based notebook bundles to Intel $(8$ Centrino ${ }^{\mathrm{TM}}$ mobile technology-based notebook bundles in 2003 . To study how wirelessenabled laptops impact productivity and work behavior, Intel studied more than 100 Intel employees in different offices around the United States by providing them with the same Intel Centrino mobile technology notebook bundles used in our migration. We tested participants in Intel's Human Factors Engineering Usability labs, gathered data from weekly activity logs kept by study participants, evaluated responses to pre- and post-surveys, evaluated actual usage patterns from the records of wireless hotspot access service providers, and conducted one-on-one interviews with study participants. We observed a productivity gain of 37.3 percent between the two systems which confirmed our business decision to migrate to wireless technology. What surprised us, though, was the pace at which our participants' work behaviors changed during the study. The key findings of the study are summarized below.

Time Slicing. Time slicing refers to the worker's ability to slice time and convert smaller and smaller portions into valuable work time. On an older notebook, an extra few minutes wouldn't have been enough to allow an employee to plug in, start up the

\footnotetext{
'Copyright $(92005$, Intel Corporation. Used with permission.
} 
system, connect to a remote network and do useful work. The new Intel Centrino mobile technology bundles, however, can quickly connect to the network, allowing the participant to check e-mail or perform a fast search on the Web between meetings. The ease of connection, wireless hotspot availability, and performance gains allowed participants to become productive in smaller units of time. Participants reported that they had a more positive sense of "being on top of their work," and were more responsive to team members, clients, and suppliers. One user said, "I had to wait during a child's appointment one evening. I went to a hotspot, pulled down my e-mail, and worked on an urgent issue. It was great to have the flexibility to do this so I didn't have to $\log$ on when I got home at 9:30 that evening."

Time Shifting. Time shifting refers to the worker's ability to distribute time around work and personal obligations and shift their work times as needed to reduce times of low or no productivity. As time slicing became second nature, workers in the study tended to become more adept at time shifting, or arranging their day to optimize effectiveness at work while managing personal obligations. Once wirelessly connected, these employees had an increasing number of places and times to effectively and productively connect to the corporate network. They could choose to work from new and different locations when those were more convenient than connecting from office or home. For example, they could more effectively manage commute time by using wireless hotspots. A user commented,

I was able to meet [an] extremely tight planning deadline while on the road for the day meeting with a client. Without Intel Centrino [mobile technology], I would have either missed [the] deadline or would have not taken advantage of the opportunity to meet with the client, which had been in the works for about two months.

Ubiquitous Wireless Use and Better Work-Life Balance. Wireless connections, great battery life, and a thinner, lighter form factor led participants to carry and rely on their notebooks much more often. Participants have developed a growing affinity for their notebooks. A user said,

I was attending my son's soccer tournament on Saturday, and work came up that needed to be finished. Luckily, I had my notebook in the trunk and was able to find a hotspot 5 minutes away. I connected and finished the work. Before I would have been forced to drive home (more than an hour each way), and would have missed most of the tournament.

We worried that participants might view the location flexibility they gained as a further encroachment of business time into personal time. However, they reported that increased mobility allowed them to flexibly and conveniently manage their work obligations and protect personal time more effectively. The added flexibility and convenience that allowed participants to manage work obligations helped them manage their personal time more effectively as well. A user commented, "I set up a wireless access point at home and I'm no longer trapped in the den. I can sit with family while I'm getting bits of work done." 
Intel is deploying more wireless enabled systems across the company based on these encouraging results. Intel continues to extend the wireless proliferation by developing platform architectures using technologies such as $802.11 \mathrm{a} / \mathrm{g}$ and Wi-Max.

\title{
REFERENCES
}

Lyytinen, K., and Yoo, Y. "Research Commentary: The Next Wave of Nomadic Computing," Information Systems Research (13:4), 4, December 2002, pp. 377-388.

Cousins, K., and Robey, D. "Patterns of Use within Nomadic Computing Environments: An Agency Perspective on Access-Anytime, Anywhere," paper presented at the Workshop on Ubiquitous Computing Environments, Case Western Reserve University, October 2003.

\begin{abstract}
ABOUT THE AUTHOR
Majorkumar Govindaraju is a Senior Human Factors Engineer at Intel Corporation. He is part of User Centered Design team within the Information Technology division in Intel and applies human factors methodologies for developing usable products. His previous work in Intel included projects aimed at finding the corporate business value of information technology products and solutions. Majorkumar has worked in the field of human factors engineering and ergonomics since 1993 and has written over 35 research publications and white papers. He obtained a Ph.D. in Industrial Engineering with emphasis in Human Factors from the University of Cincinnati. Majorkumar can be reached at majorkumar.govindaraju@intel.com.

David Sward is a Staff Human Factors Engineer at Intel Corporation, Chandler. David has established and managed cross-disciplinary teams that apply user-centered design to the development of Intel products and for services from Intel's Information Technology division. He is currently engaged with several companies, academic institutions, industry forums, and consulting firms to develop processes that measure the business value of information technology. David has worked in the field of human factors engineering since 1991 and is an adjunct faculty member in the Applied Psychology program at Arizona State University East, teaching classes in human factors engineering, human-computer interaction, and the usability engineering lifecycle. David can be reached at david.s.sward@intel.com.
\end{abstract}




\section{Part 7}

Panels 